EXTENDED REPORT

\title{
Which patients with ankylosing spondylitis should be treated with tumour necrosis factor inhibiting therapy? A survey among Dutch rheumatologists
}

\author{
R Landewé, B Rump, D van der Heijde, S van der Linden
}

Ann Rheum Dis 2004;63:530-534. doi: 10.1136/ard.2003.011130

See end of article for authors' affiliations

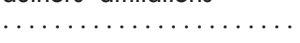

Correspondence to: Robert B M Landewé, Department of Internal Medicine/Rheumatology, PO Box 5800, 6202 AZ Maastricht, Netherlands; rlan@sint.azm.nl

Accepted 21 July 2003

\begin{abstract}
Aim: To determine the criteria considered important by Dutch rheumatologists in judging whether a patient with ankylosing spondylitis should start tumour necrosis factor (TNF) blocking therapy.

Methods: 19 Dutch rheumatologists were asked to prioritise various demographic and clinical features for their importance in judging whether a patient should be treated with TNF blocking therapy. In addition, nine Dutch physicians who had referred patients with ankylosing spondylitis for inclusion in an ongoing long term observational study (OASIS) were asked to determine on the basis of case record review for each of their patients whether or not TNF blocking therapy would be considered appropriate.

Results: The variables considered most important were: rate of development of functional impairment; physician's global assessment of current disease activity; physician's global assessment of cumulative disease activity; presence of hip arthritis; physician's global assessment of disease severity. Analysis of the OASIS data (79 patients) showed that patients in whom TNF blocking therapy was considered justified $(n=24 ; 30 \%)$ differed significantly from those in whom it was not considered justified in: patient reported disease activity; functional impairment; spinal mobility; radiographic damage score. Multivariate analysis showed that male sex, function, and radiographic damage were the only independent determinants of a decision to start TNF blocking drugs.

Conclusions: Physicians reported that disease activity, function, and severity were critically important in judging whether to start TNF blocking therapy. In practice, they based their decision more on severity than on activity. They were able to select patients with a high level of radiographic damage, which suggests that this feature captures other domains such as disease activity, spinal mobility, and function.
\end{abstract}

U ntil recently, the treatment of patients with ankylosing spondylitis consisted of education, regular exercise for individual patients or in groups, other types of physiotherapy (including hydrotherapy), and an appropriate dose of non-steroidal anti-inflammatory drugs (NSAID). ${ }^{12}$ Unlike the situation in rheumatoid arthritis, disease modifying anti-rheumatic drugs (DMARD) have not been shown to be effective for the axial manifestations of the disease. ${ }^{3}$

The pharmacotherapeutic armamentarium was dramatically changed by the introduction of tumour necrosis factor (TNF) blocking drugs. Etanercept and infliximab appeared to be highly effective in suppressing the signs and symptoms of ankylosing spondylitis, as shown by two recent independent phase 2 clinical trials. ${ }^{4}{ }^{5}$ Phase 3 trials, which investigate the potential of TNF blocking drugs to suppress disease activity and prevent the progression of structural damage, are now under way.

Anticipating that these agents will be registered for clinical use, it is important to determine which patients will benefit most from their use, as they are very expensive and their long term effects are unknown.

To reach a consensus on this issue and to develop guidelines, the Assessments in Ankylosing Spondylitis (ASAS) working group recently organised an expert meeting in Berlin. In preparation for this meeting, we explored the views of a representative sample of Dutch rheumatologists about which types of patient with ankylosing spondylitis should be treated with TNF blocking drugs (exploratory approach). We then employed an ongoing cohort study of patients with ankylosing spondylitis to investigate whether decisions on the appropriateness of TNF blocking therapy in the individual patient can be captured by demographic information, information on work status, and instruments reflecting disease activity and disease severity (individualised approach).

\section{METHODS \\ Exploratory approach}

We recruited 19 Dutch rheumatologists working in different regions of the Netherlands, and representing both university hospital (including tertiary referral centres) and general hospital working environments. They were asked to prioritise various items reflecting demographic data, socioeconomic status, disease specific comorbidity, and reports by both patients and physicians on specific characteristics of ankylosing spondylitis for their importance in determining whether or not a patient with this disease should be treated with TNF blocking drugs. None of the rheumatologists had been involved in any clinical trial with these agents in ankylosing spondylitis, and their experience was only anecdotal.

The rheumatologists were asked to make their decision under the following assumptions:

- TNF blocking drugs are available on demand;

- the cost of TNF blocking drugs is completely reimbursed;

\footnotetext{
Abbreviations: BASDAl, Bath ankylosing spondylitis disease activity index; ISSAS, "International start TNF blocker study ankylosing spondylitis"; OASIS, "Outcome in ankylosing spondylitis international study"; SASSS, Stoke ankylosing spondylitis spinal score; TNF, tumour necrosis factor
} 
- patients may expect a 50\% decrease in BASDAI (the Bath ankylosing spondylitis disease activity index) in more than $50 \%$ of the patients (based on the results of two phase 2 clinical trials $)^{4}$;

- long term toxicity is unknown.

Prioritisation was done by rank ordering the variables by perceived importance, from 1 (most important) to 5 (least important), and by scoring the importance per item on a nominal four point scale $(0$, not important to +++ , very important).

The items were as follows: age; sex; disease duration; occupation ("white collar" (office job) or "blue collar" (physical job)); loss of job during the past 12 months; permanent disability pension (after a period of 12 months of continuous sick leave, a full or partial work disability can be granted in the Netherlands); history or the presence of extraspinal features (such as hip arthritis, shoulder arthritis, or arthritis in other peripheral joints, enthesitis, inflammatory bowel disease, or acute anterior uveitis); limitation of spinal function (lumbar spine, thoracic spine, and cervical spine were inquired about separately); grade of syndesmophyte bridging (from no bridging to complete bridging); rate of development of functional impairment (global impression); rate of development of structural radiographic damage (global impression); increased acute phase reactants (C reactive protein and erythrocyte sedimentation rate); NSAID tolerance and efficacy; tolerance and efficacy of previous DMARDs; efficacy of current DMARDs; physician's global assessment of current disease activity; physician's global assessment of cumulative disease activity; and physician's global assessment of cumulative disease severity.

The rheumatologists were further encouraged to mention any other factors related to their decision to start TNF blocking therapy, and rank them accordingly.

The analysis was descriptive. Variables were rank ordered by the percentage of rheumatologists mentioning this variable, by a weighted score of importance (not important, 0 to very important, 4); and by "top five" rank order by every rheumatologist.

\section{Individualised approach: cohort analysis}

For the analysis on how physician's anti-TNF treatment decisions for individual patients can best be captured in measurable constructs, use was made of the cohort from the OASIS study (outcome in ankylosing spondylitis international study). OASIS is an ongoing prospective study of consecutive patients with ankylosing spondylitis from three different countries (Belgium, France, and the Netherlands). ${ }^{6}$ Patients were first recruited in 1997. Recruitment was complete within three months, and patients were followed consecutively by at least annual assessments. The assessment profile included all instruments selected by the Ankylosing Spondylitis Assessment Working Group as a core set to assess outcome in ankylosing spondylitis, ${ }^{89}$ plus other widely used instruments, such as BASDAI, as well as extensive information on the socioeconomic situation, comorbidity, and disease severity.

The study described here was limited to the Dutch patients only. The data from the last available follow up visit were used for further analysis. These data were collected independently without reference to the treating physicians, and the findings were not communicated with them. As an example, radiography of the spine will be mentioned here. The treating rheumatologist was not aware of the damage score that was assigned by us to that patient (for example, 70 modified SASSS (Stoke ankylosing spondylitis spinal score) units-a score which was used in the analyses). But it is possible, though not obligatory, that the rheumatologist had insight in the radiologist's report that "there are signs of spondylitis anteriorly, with small syndesmophytes at different levels."

The treating physician of each patient was asked by one of us (BR) to use their clinical insight to judge whether or not a patient should be treated with TNF blocking drugs, based on the same assumptions as for the exploratory approach above. The treating physician was allowed, but not obliged, to study the medical dossier of that particular patient in order to make his decision in case of any doubt.

\section{Data analysis}

The primary analysis was descriptive: means (SD), medians (centiles), and frequencies, stratified by TNF blocking therapy (yes $v$ no) were calculated as appropriate. Univariate between-group differences were tested statistically by two sample $t$ tests, the Mann-Whitney two sample test, or $\chi^{2}$ tests (Fisher's exact test) as appropriate.

To compare between-group differences across variables, the mean between-group difference for each variable was standardised by dividing it by the standard deviation of the mean between-group difference. Skewed data were logarithmically transformed before standardising. Standardised mean differences were rank ordered, so that the variables that were ranked highest showed the greatest between-group contrast.

Backward selection logistic regression analysis was done to investigate which variables contributed independently to the decision on whether a patient was an appropriate candidate for TNF blocking therapy.

\section{RESULTS}

\section{Exploratory approach}

Nineteen rheumatologists completed the questionnaire on the variables potentially contributing to the decision to start TNF blocking therapy. These rheumatologists estimated that

Table 1 Variables prioritised by 19 rheumatologists with respect to their contribution in the decision to start TNF blocking therapy in patients with ankylosing spondylitis

\begin{tabular}{|c|c|c|}
\hline & $\begin{array}{l}\text { Percentage } \\
\text { mentioning this } \\
\text { variable in their } \\
\text { top } 5\end{array}$ & $\begin{array}{l}\text { Rank order based } \\
\text { on weighted score } \\
\text { (top 10) }\end{array}$ \\
\hline $\begin{array}{l}\text { Rate of development of } \\
\text { functional impairment }\end{array}$ & 89 & 1 \\
\hline $\begin{array}{l}\text { Rate of development } \\
\text { of radiographic }\end{array}$ & & \\
\hline $\begin{array}{l}\text { progression } \\
\text { Physician's assessment }\end{array}$ & 81 & 6 \\
\hline \multicolumn{3}{|l|}{ Physician's assessment } \\
\hline activity & 77 & 2 \\
\hline General pain (current) & 75 & 6 \\
\hline Night pain (current) & 75 & 10 \\
\hline \multicolumn{3}{|l|}{ Physician's assessment } \\
\hline severity of disease & 75 & 5 \\
\hline Hip arthritis & 75 & 4 \\
\hline \multicolumn{3}{|l|}{ Morning stiffness } \\
\hline (current) & 68 & 8 \\
\hline Arthritis shoulder & 63 & - \\
\hline \multirow{2}{*}{\multicolumn{3}{|c|}{ Physician's assessment of }} \\
\hline & & \\
\hline $\begin{array}{l}\text { cumulative disease activity } \\
\text { Impairment of spinal }\end{array}$ & 61 & 3 \\
\hline \multicolumn{3}{|l|}{$\begin{array}{l}\text { mobility } \\
\text { Efficacy of current }\end{array}$} \\
\hline NSAID treatment & 56 & - \\
\hline Sick leave (12 months) & 54 & - \\
\hline \multicolumn{3}{|l|}{ Patient's assessment of } \\
\hline
\end{tabular}


Table 2 Demographics and disease history (means (SDs) or percentages)

\begin{tabular}{|c|c|c|c|}
\hline & \multicolumn{2}{|c|}{$\begin{array}{l}\text { Anti-TNF indicated by the } \\
\text { treating rheumatologist: }\end{array}$} & \multirow[b]{2}{*}{$\begin{array}{l}\text { p Value } \\
\text { (difference }\end{array}$} \\
\hline & $\begin{array}{l}\text { Yes }(n=24) \\
(30 \%)\end{array}$ & $\begin{array}{l}\text { No }(n=55) \\
(70 \%)\end{array}$ & \\
\hline Age (years) & $52.2(11.6)$ & $52.4(11.9)$ & 0.74 \\
\hline $\operatorname{Sex}(M)$ & 62 & 73 & 0.30 \\
\hline \multicolumn{4}{|c|}{ Current disease duration } \\
\hline ( & $20.4(11.6)$ & $17.2(14.7)$ & 0.25 \\
\hline History of uveitis (yes/no)* & 33 & 14 & 0.10 \\
\hline HLA-B27 (present) & 88 & 83 & 0.99 \\
\hline Paid job (yes) & 42 & 50 & 0.80 \\
\hline
\end{tabular}

Values are mean (SD) or per cent.

*Inflammatory bowel disease, psoriasis, and other spondyloarthropathy related conditions were very rare or absent.

a median of $10 \%$ (range $5 \%$ to $25 \%$ ) of the patients with ankylosing spondylitis under their care were appropriate candidates for TNF blocking therapy. The results of the question on prioritising the variables according to their contribution to treatment decision making are shown in table 1 .

Rheumatologists considered a rapid decline in functional capacity as well as rapid radiographic progression to be the most important indicators for starting treatment with TNF blocking drugs in patients with ankylosing spondylitis. Fewer rheumatologists reported current and cumulative disease activity as assessed by the physician as important, but the rheumatologists who did give these variables a relatively high weight ranked them 2 and 3 in the weighted scores. Extraspinal disease manifestations_-such as hip, shoulder, and other kinds of peripheral arthritis-were also ranked high. Although patient derived variables such as general pain and night pain were mentioned by $75 \%$ of the rheumatologists in their top 5, their importance was rated as modest (rank 6/10), and the patient's overall assessment of disease activity was not considered a very important determinant in the decision to start TNF blocking drugs (mentioned by $51 \%$ of rheumatologists only).

\section{The cohort analysis}

A judgment by their treating physicians $(n=9)$ on the appropriateness of TNF blocking therapy could be obtained for 79 patients. Of these, $24(30 \%)$ were considered a candidate for this kind of treatment. Tables 2 to 6 show how these two groups (candidates $v$ non-candidates) differed with respect to demographic data and comorbidity (table 2), patient derived assessments (table 3 ), assessments of spinal mobility (table 4), physician derived assessments (table 5), and radiology (table 6).

Patients with indications for TNF blocking therapy tended more often to have a history of uveitis and were more often HLA-B27 carriers than patients without such indications, according to their treating physicians. Physicians did not base their decision on whether or not the patient was in work. All patient-derived assessments, including BASDAI (disease activity) and BASFI (function), scored higher on average, and the difference was statistically significant in many cases. Spinal mobility, as assessed by several different tests, was worse in the patients with indications for TNF blocking

Table 3 Disease activity and function: the patients' perspective

\begin{tabular}{|c|c|c|c|c|c|}
\hline & \multicolumn{5}{|c|}{ Anti-TNF indicated by the treating rheumatologist } \\
\hline & \multicolumn{2}{|c|}{ Yes $(n=24)(32 \%)$} & \multicolumn{2}{|c|}{ No $(n=55)(70 \%)$} & \multirow{2}{*}{$\begin{array}{l}\text { p Value } \\
\text { (difference) }\end{array}$} \\
\hline & Mean & SD & Mean & SD & \\
\hline BASDAl $(\mathrm{cm})$ & 4.6 & 2.5 & 3.1 & 2.2 & 0.01 \\
\hline Fatigue & 5.5 & 2.9 & 4.3 & 3.0 & 0.20 \\
\hline Pain (neck, back, hips) & 5.7 & 2.7 & 4.0 & 2.7 & 0.012 \\
\hline Pain (peripheral joints) & 3.8 & 3.3 & 2.1 & 2.2 & 0.034 \\
\hline Pain (enthesopathy) & 3.9 & 3.3 & 2.4 & 2.6 & 0.062 \\
\hline Morning stiffness (severity) & 4.8 & 3.1 & 2.9 & 2.5 & 0.014 \\
\hline Morning stiffness (duration) & 4.3 & 3.2 & 2.9 & 2.7 & 0.045 \\
\hline BASFI $(\mathrm{cm})$ & 5.5 & 2.2 & 3.6 & 2.4 & 0.002 \\
\hline BASG (last week) (cm) & 5.1 & 2.5 & 3.2 & 2.5 & 0.003 \\
\hline BASG $(6$ months) $(\mathrm{cm})$ & 5.6 & 2.8 & 3.6 & 2.6 & 0.003 \\
\hline $\mathrm{DFI}(\mathrm{mm})$ & 30.4 & 12.9 & 21.2 & 14.6 & 0.01 \\
\hline Spinal pain $(\% \geqslant 2)$ & 48 & & 28 & & 0.11 \\
\hline
\end{tabular}

Table 4 Spinal mobility

\begin{tabular}{|c|c|c|c|c|c|}
\hline & \multicolumn{5}{|c|}{ Anti-TNF indicated by the treating rheumatologist } \\
\hline & \multicolumn{2}{|c|}{ Yes $(n=24)(30 \%)$} & \multicolumn{2}{|c|}{ No $(n=55)(70 \%)$} & \multirow{2}{*}{$\begin{array}{l}\text { p Value } \\
\text { (difference) }\end{array}$} \\
\hline & Mean & SD & Mean & SD & \\
\hline Chest expansion $(\mathrm{cm})$ & 2.0 & 1.3 & 3.1 & 2.0 & 0.005 \\
\hline Fingers to floor $(\mathrm{cm})$ & 18.2 & 16.5 & 12.1 & 11.8 & 0.13 \\
\hline Occiput to wall $(\mathrm{cm})$ & 7.0 & 7.6 & 4.8 & 6.9 & 0.21 \\
\hline Tragus to wall $(\mathrm{cm})$ & 17.4 & 5.2 & 15.2 & 5.8 & 0.12 \\
\hline Modified Schober $(\mathrm{cm})$ & 2.7 & 1.6 & 3.6 & 1.7 & 0.03 \\
\hline Cervical rotation (degrees) & 46 & 25 & 59 & 23 & 0.026 \\
\hline Intermalleolar distance $(\mathrm{cm})$ & 93 & 14 & 100 & 23 & 0.15 \\
\hline Lateral spinal flexion $(\mathrm{cm})$ & 7.1 & 3.1 & 10.3 & 5.5 & 0.003 \\
\hline BASMI & 3.6 & 0.9 & 2.8 & 1.5 & 0.006 \\
\hline
\end{tabular}


Table 5 Disease activity: physician's perspective

\begin{tabular}{|c|c|c|c|c|c|}
\hline & \multicolumn{5}{|c|}{ Anti-TNF therapy indicated by the treating rheumatologist } \\
\hline & \multicolumn{2}{|c|}{ Yes $(n=24)(30 \%)$} & \multicolumn{2}{|c|}{ No $(n=55)(70 \%)$} & \multirow{2}{*}{$\begin{array}{l}\text { p Value } \\
\text { (difference) }\end{array}$} \\
\hline & Median & $25 \% ; 75 \%$ & Median & $25 \%, 75 \%$ & \\
\hline Assessor's global (cm) & $2.3^{*}$ & $1.5^{\star}$ & 1.9 & 1.3 & 0.39 \\
\hline Tender joint count & 2 & $0 ; 10$ & 1 & $0 ; 5$ & 0.40 \\
\hline Swollen joint count & 0 & $0 ; 0$ & 0 & $0 ; 0$ & 0.33 \\
\hline ESR (mm) & 14 & $9 ; 34$ & 9 & $5 ; 21$ & 0.11 \\
\hline CRP (mg/dl) & 14 & $6 ; 26$ & 9 & $6 ; 12$ & 0.067 \\
\hline
\end{tabular}

\section{Table 6 Radiography}

\begin{tabular}{|c|c|c|c|c|c|}
\hline & \multicolumn{5}{|c|}{ Anti-TNF indicated by the treating rheumatologist } \\
\hline & \multicolumn{2}{|c|}{ Yes $(n=24)(30 \%)$} & \multicolumn{2}{|c|}{ No $(n=55)(70 \%)$} & \multirow{2}{*}{$\begin{array}{l}\text { p Value } \\
\text { (difference) }\end{array}$} \\
\hline & median & $25 \% ; 75 \%$ & median & $25 \% ; 75 \%$ & \\
\hline $\begin{array}{l}\text { Modified SASSS (status score)* } \\
\text { Modified SASSS }(4 \text { years }\end{array}$ & 22 & $13 ; 40$ & 10 & $1 ; 32$ & 0.001 \\
\hline progression)† & 3 & $0 ; 8$ & 0 & $0 ; 5$ & 0.087 \\
\hline
\end{tabular}

treatment, as were the radiological appearances (both status score and progression score). Patient derived assessmentsincluding joint counts and acute phase reactants-did not differ between the two subgroups.

Table 7 shows that the modified SASSS (radiology) status score and the BASFI (function), as single variables, discriminated best between patients with and without a physician reported indication for TNF blocker treatment, followed by lumbar lateral flexion (spinal mobility), BASG (in the previous week), and BASG (in the previous six months) (patient's global assessments of wellbeing).

Table 8 shows the results of the multivariate logistic regression analysis in which all variables presented in tables 2 to 6 were investigated for their independent potential to explain the physician's judgment about the appropriateness of prescribing TNF blocking therapy. Physicians appeared to assign TNF blocking therapy preferentially to male rather than to female patients, and independently to those characterised by a relatively high level of radiological damage and those with impaired cervical spinal mobility. None of the other variables contributed independently to explaining the variation in assignment.

\section{DISCUSSION}

Confronted with the question as to what kind of patients with ankylosing spondylitis should be treated with TNF blocking therapy, rheumatologists-if asked outside their office, that is, if not actually facing such a situation with one of their patients-say that they base their decision on factors such as rapid functional deterioration, rapid radiographic progression, a high level of current and previous disease activity, and the presence of peripheral arthritis. When tested with actual patient records, however, they appear to prefer TNF blocking therapy for patients with advanced disease, reflected by high scores on the assessments for spinal mobility and radiographic damage, rather than active disease, with or without extraspinal involvement. Apart from that, the multivariate analysis showed that they would assign a higher priority to male patients, perhaps reflecting the general appreciation that male patients with ankylosing spondylitis have a worse prognosis

We found a clear discrepancy between what physicians think they should do and what they actually do if confronted with the patient's records. The rationale for assigning TNF blocking treatment to patients with a high rate of functional

Table 7 Standardised mean differences (highest to lowest)

\begin{tabular}{ll}
\hline & $\begin{array}{l}\text { Standardised mean } \\
\text { difference* }\end{array}$ \\
Variable & 4.10 \\
\hline Modified SASSS status score & 3.22 \\
BASFI & 3.07 \\
Lateral flexion & 3.06 \\
BASG (last week) & 3.05 \\
BASG (6 months) & 2.86 \\
BASMI & 2.64 \\
DFI & 2.64 \\
BASDAI & 2.48 \\
Chest expansion & 2.21 \\
Modified Schober & 2.20 \\
Cervical rotation & 1.87 \\
Modified SASSS progression score & 1.85 \\
Spinal pain & 1.65 \\
ESR & 1.58 \\
Fingers to floor distance & 1.52 \\
Tragus to wall & 1.48 \\
Intermalleolar distance & 1.40 \\
C reactive protein & 1.33 \\
Occiput to wall & 1.15 \\
Swollen joint count & 1.05 \\
Tender joint count & \\
\hline \multirow{2}{*}{ *Quotient of mean group difference and standard error of } \\
the mean group difference, joint counts, ESR, CRP, and \\
modified SASSS (status score and progression score) were \\
logarithmically transformed. \\
BASDAl, Bath ankylosing spondylitis disease activity index; \\
BASFI, Bath ankylosing spondylitis functional index; BASG, \\
Bath ankylosing spondylitis global assessment of disease \\
activity; BASMI, Bath ankylosing spondylitis metrology index; \\
DFI, Dougados functional index; ESR, erythrocyte \\
sedimentation rate; SASSS, Stoke ankylosing spondylitis \\
spinal score. & \\
& \\
\hline
\end{tabular}


Table 8 Logistic regression analysis to explain a current indication for anti-TNF therapy

\begin{tabular}{llll}
\hline Variables* & Odds ratio & $\mathbf{9 5 \%} \mathbf{C l}$ & p Value \\
\hline Sex (male) & 4.3 & 1.1 to 18 & 0.039 \\
BASFI (per cm) & 1.3 & 0.99 to 1.8 & 0.054 \\
$\begin{array}{l}\text { Modified SASSS (units) } \\
\text { (above median) }\end{array}$ & 10 & 2.1 to 47 & 0.004 \\
\hline
\end{tabular}

*Variables that contributed significantly were selected by backwards selection logistic regression analysis.

BASFI, Bath ankylosing spondylitis functional index; $\mathrm{Cl}$, confidence

interval; SASSS, Stoke ankylosing spondylitis spinal score.

deterioration and radiographic progression may be that deterioration can be halted by appropriate treatment. The rationale of starting this type of treatment preferentially in patients with advanced disease is more questionable-there is no indication that TNF blocking therapy can undo established radiographic damage, and trial results have shown that impairment of spinal mobility is only partly reversible. A more likely explanation for the phenomenon that physicians prioritise patients with advanced disease may be that measures reflecting severity (radiographic damage, spinal mobility) adequately capture other domains, among which are disease activity and function, both from the patient's perspective and from the physician's perspective; in other words, patients with more advanced, severe disease have by definition greater disease activity, on the assumption that a high level of cumulative disease activity has led to the present situation. There are two arguments underscoring this concept. First, the assessments that actually reflect disease activity scored significantly higher in the TNF assigned group. Second, radiographic damage was revealed as the most important discriminating factor, though the physicians were not aware of the actual radiographic score (because these data were not available in the case records), so they must have based their decision on other constructs directly related to radiological damage. An example might be that physicians could have an intuitive impression about spinal mobility in an individual patient, and spinal mobility is associated with radiographic damage.

Another discrepancy is that physicians mentioned that they placed high value on the presence of extraspinal disease (arthritis of the peripheral joints). We did not encounter this tendency in the cohort analysis, on either univariate or multivariate analysis. Again, the explanation may be that peripheral arthritis is already captured by other domains. We have shown recently that patients with peripheral arthritis have generally greater disease activity than patients without arthritis. ${ }^{10}$ Another explanation may be that the physicians simply did not recall whether or not there was, or had been, peripheral arthritis.

It is also interesting to investigate the factors that did not contribute to the decision to assign patients to TNF blocking therapy. Patient derived measures of disease activity played a minor role in physicians' perception, though the global assessment of wellbeing made by the patient appeared to be contributory. An important limitation of this study is that physicians were asked to make their judgment without consulting the patient. Results may have been biased towards physician derived (and physician remembered) assessments, and this could explain the relative dearth of patient derived assessments in the set of contributory factors. Another factor that we thought beforehand would be contributory-whether or not the patient was in work-turned out to be unimportant with respect to the decision to assign TNF blocking drugs in either type of analysis. Labour force participation and sick leave are strongly subjected to national legislation, and the interpretation of these results should therefore be cautious.

The context of this study does not reflect reality. In the real world, the decision to start TNF blocking drugs will be the result of communication between patient and physician. Both parties will bring in their own conditions and priorities, and the net result of this negotiating process will be a more balanced judgment about the appropriateness of starting TNF blocking drugs, as opposed to the findings in this exploratory study which emphasise physicians' opinions. Nevertheless, these results - and those of the "international start TNF blocker study ankylosing spondylitis" (ISSAS), which are expected in the second part of 2003-may shed light on how physicians view the need to start TNF blocking drugs, and can therefore be an indication for recommendations and guidelines for TNF blocking therapy in the future.

\section{Authors' affiliations}

R Landewé, B Rump, D van der Heijde, S van der Linden, University Hospital Maastricht, Department of Internal Medicine/Rheumatology, Maastricht, Netherlands

\section{REFERENCES}

1 Linden Svan der, van Tubergen A, Hidding A. Physiotherapy in ankylosing spondylitis: what is the evidence? Clin Exp Rheumatol 2002;20:S60-4.

2 Tubergen $A$ van, Landewé $R$, van der Heijde $D$, Hidding A, Wolter $N$, Asscher $M$, et al. Combined spa-exercise therapy is effective in patients with ankylosing spondylitis: a randomized controlled trial. Arthritis Rheum 2001;45:430-8.

3 van Tubergen AM, Landewe R, van der Linden S. Spondylarthropathies: options for combination therapy. Springer Semin Immunopathol 2001;23:147-63.

4 Braun J, Brandt J, Listing J, Zink A, Alten R, Golder W, et al. Treatment of active ankylosing spondylitis with infliximab: a randomised controlled multicentre trial. Lancet 2002;359:1187-93.

5 Gorman JD, Sack KE, Davis JD. Treatment of ankylosing spondylitis by inhibition of tumor necrosis factor alpha. N Engl J Med 2002;346:1349-56.

6 Spoorenberg A, van der Heijde D, de Klerk E, Dougados M, der Vlam K, Mielants $\mathrm{H}$, et al. A comparative study of the usefulness of the Bath Ankylosing Spondylitis Functional Index and the Dougados Functional Index in the assessment of ankylosing spondylitis. J Rheumatol 1999;26:961-5.

7 Spoorenberg A, van der Heijde D, de Klerk E, Dougados M, der Vlam K, Mielants $\mathrm{H}$, et al. Relative value of erythrocyte sedimentation rate and $\mathrm{C}$ reactive protein in assessment of disease activity in ankylosing spondylitis. $J$ Rheumatol 1999;26:980-4.

8 van der Heijde D, Calin A, Dougados M, Khan MA, van der Linden S, Bellamy N, et al. Selection of instruments in the core set for DC-ART, SMARD, physical therapy, and clinical record keeping in ankylosing spondylitis. Progress report of the ASAS Working Group. Assessments in Ankylosing Spondylitis. J Rheumatol 1999;26:951-4.

9 van der Heijde D, Braun J, McGonagle D, Siegel J, et al. Treatment trials in ankylosing spondylitis: current and future considerations. Ann Rheum Dis 2002;61:iii24-32.

10 Heuft-Dorenbosch L, van Tubergen A, Spoorenberg A, Landewé R, Dougados $M$, Mielants $H$, et al. Is the BASDAl an appropriate instrument to measure disease activity in ankylosing spondylitis patients with and without peripheral arthritis? Arthritis Rheum (in press). 